\title{
Unusual extension of sacral hiatus - A case report
}

\author{
Jugesh Khanna, Renu Chauhan \\ Professor, Associate Professor Department of Anatomy UCMS and GTB Hospital Dilshad Garden Delhi- \\ 110095, India
}

\begin{abstract}
The laminae of fifth and sometimes fourth sacral vertebrae fail to fuse posteriorly in the sagittal plane leading to formation of a deficiency in the posterior wall of the sacral canal commonly known as sacral hiatus. During osteology demonstration class of MBBS students of the Department of Anatomy, U.C.M.S and G.T.B Hospital, Delhi, we noticed a sacrum in which sacral hiatus was extending to a level just inferior to the spinous process of second sacral vertebra. Review of literature suggested that the extent of sacral hiatus could be variable. To our knowledge, extension of sacral hiatus just inferior to spinous process of second sacral vertebra has not been described in the past. Familiarity with such kind of variation may help in administration of caudal epidural anaesthesia.
\end{abstract}

Key words: Anaesthesia, Analgesia, Caudal epidural block, Sacral canal, Sacral hiatus

\section{Introduction}

Caudal epidural block (CEB) is necessary in various clinical procedures for providing analgesia and anaesthesia in the specific region of surgery. This involves injecting the drug into the epidural space through the sacral hiatus . Sacral hiatus is a deficiency in the lower part of the posterior wall of sacral canal (Fig. 1). It is covered by skin, subcutaneous fat and sacrococcygeal membrane. The dura mater and the subarachnoid space usually end at the level of second sacral vertebra but sometimes the dural sac may ends as high as the fifth lumbar or third sacral vertebra. In adults it is occasionally difficult to determine the location of the sacral hiatus and subsequently the caudal epidural space. ${ }^{1}$ The apex of sacral hiatus is extending to a level just inferior to spinous process of second sacral vertebra in the present case. There are likely chances that the drug injected for caudal epidural block may enter the subarachnoid space if dural sac and subarachnoid space are extending till the level of third sacral vertebra as suggested by Patil et al., (2012) ${ }^{1}$. Clinicians should also be aware of this variation so as to avoid injecting an analgesic or anaesthetic drug into subarachnoid space while injecting it into epidural space.

\section{II. . Case Report}

Accidentally, we found a sacrum in which the sacral hiatus extended to a level just inferior to the spinous process of second sacral vertebra. Importance of its clinical relevance has been discussed in the paper.

\section{Discussion And Conclusion}

The deficiency in the posterior wall of sacral canal is known as sacral hiatus. Laminae of the fifth and sometimes fourth sacral vertebrae fail to meet behind in the mid line resulting in formation of sacral hiatus (Fig. 1). ${ }^{2,3,4,5,6}$ Apex of sacral hiatus was most commonly observed at the level of $4^{\text {th }}$ sacral vertebra. ${ }^{7,8,9}$ In the present study the apex of sacral hiatus extended to a level just inferior to the spinous process of second sacral vertebra (Fig. 2). The sacral hiatus contains lower sacral and coccygeal nerve roots, filum terminale externa and fibrofatty tissue. ${ }^{7}$ If the sacral hiatus extends high up as is seen in the present case then it may contain third, fourth and fifth sacral nerve roots also apart from it containing the usual structures. These nerve roots are then exposed and thus are liable to be damaged by any trivial injury in the regional area. This could ultimately result in some kind of urinary bladder or rectal pathology.

Injection of a drug into the epidural space through the sacral hiatus is involved in caudal epidural block for providing anaesthesia and analgesia in various clinical settings. ${ }^{8,}{ }^{10,11}$ Sekiguchi et al (2004) ${ }^{8}$, Kumar $(1992)^{9}$ and Trotter et al (1947) ${ }^{12}$ are of the opinion that the success of caudal epidural anaesthesia depends on anatomical variations of sacral hiatus. Knowledge of this unusual extension of sacral hiatus may be helpful to the radiologists in interpreting the radiographs of sacral spine. Orthopaedicians must be aware of such a variation for successful administration of caudal epidural block. Physicians must also be aware of this developmental anomaly while treating a case of neurological involvement of urinary bladder or rectum.. This piece of information may be useful to Orthopaedic surgeons and neurosurgeons while operating at the lower back. 


\section{References}

[1]. Patil D, S; Jadav, H. R; Binodkumar; Mehta, C. D Patel V D. Anatomical study of sacral hiatus for caudal epidural block.National Journal of Medical Research, 2 (3):272-275, 2012

[2]. Standring, S.; Gray's Anatomy. 40 ${ }^{\text {th }}$ Ed. Churchill Livingstone, Edinburgh, UK, 2008.p.724.

[3]. Keith, L. Moore; Anne, M. R. Agur \& Arthur F. Dalley.; Essential Clinical Anatomy. $4^{\text {th }}$ Ed. Lippincott Williams \& Wilkins, Wolter Kluwer, Baltimore, Philadelphia, 2011.p.283

[4]. Keith, L. Moore; Arthur, F. Dalley \& Anne, M. R. Agur.; Clinically Oriented Anatomy. $6^{\text {th }}$ Ed. Lippincott Williams \& Wilkins, Wolter Kluwer, Baltimore, Philadelphia, 2009.p.451.

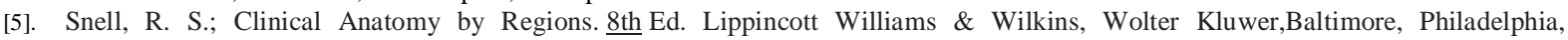
2008..p.310.

[6]. Snell, R. S.; Clinical Anatomy by Systems. ${ }^{1 \text { st }}$ Ed. Lippincott Williams \& Wilkins, Wolter Kluwer , Baltimore, Philadelphia, 2007.p.317.

[7]. Nagar, S. K. A Study of Sacral Hiatus in Dry Human Sacra. J.Anat. Soc. India, 53(2): 18-21, 2004.

[8]. Sekiguchi, M; Yabuki, S; Saton, K \& Kikuchi, S. An anatomical study of the sacral hiatus: a basis for successful caudal epidural block. Clin. J. Pain., 20(1): 51-54, 2004

[9]. Vinod, Kumar; Pandey, S. N; Bajpai, R. N; Jain, P. N \& Longia, G. S. Morphometrical study of sacral hiatus. Journal of Anatomical Society of India, 41 (1):7-13, 1992.

[10]. Chen, P. C ; Tang, S. F. T ; Hsu, T. C. et al. Ultrasound guidance in caudal epidural needle placement. Anesthesiology, 101: 181-4, 2004.

[11]. Edwards, W. B; Hingson, R. A. Continuous caudal anaesthesia in obstetrics. American journal of surgery, 57:459-464, 1942.

[12]. Trotter, M. Variations of the sacral canal; Their significance in the administration of caudal analgesia. Anesthesia and analgesia, 26 (5): 192-202, 1947

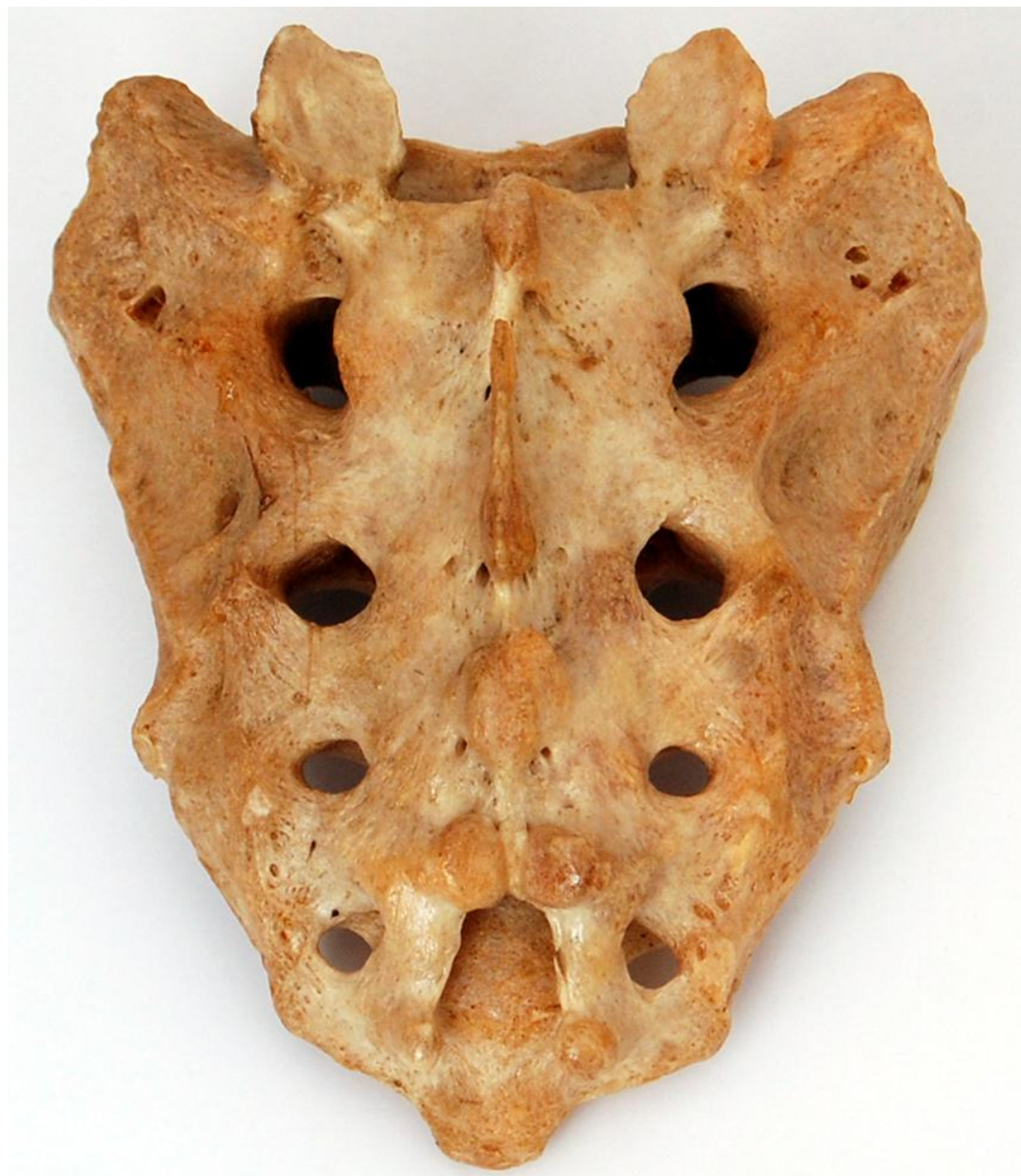

Figure: 1- Showing sacral hiatus formed due to failure of fusion of laminae of fifth sacral vertebra in the midline posteriorly. 


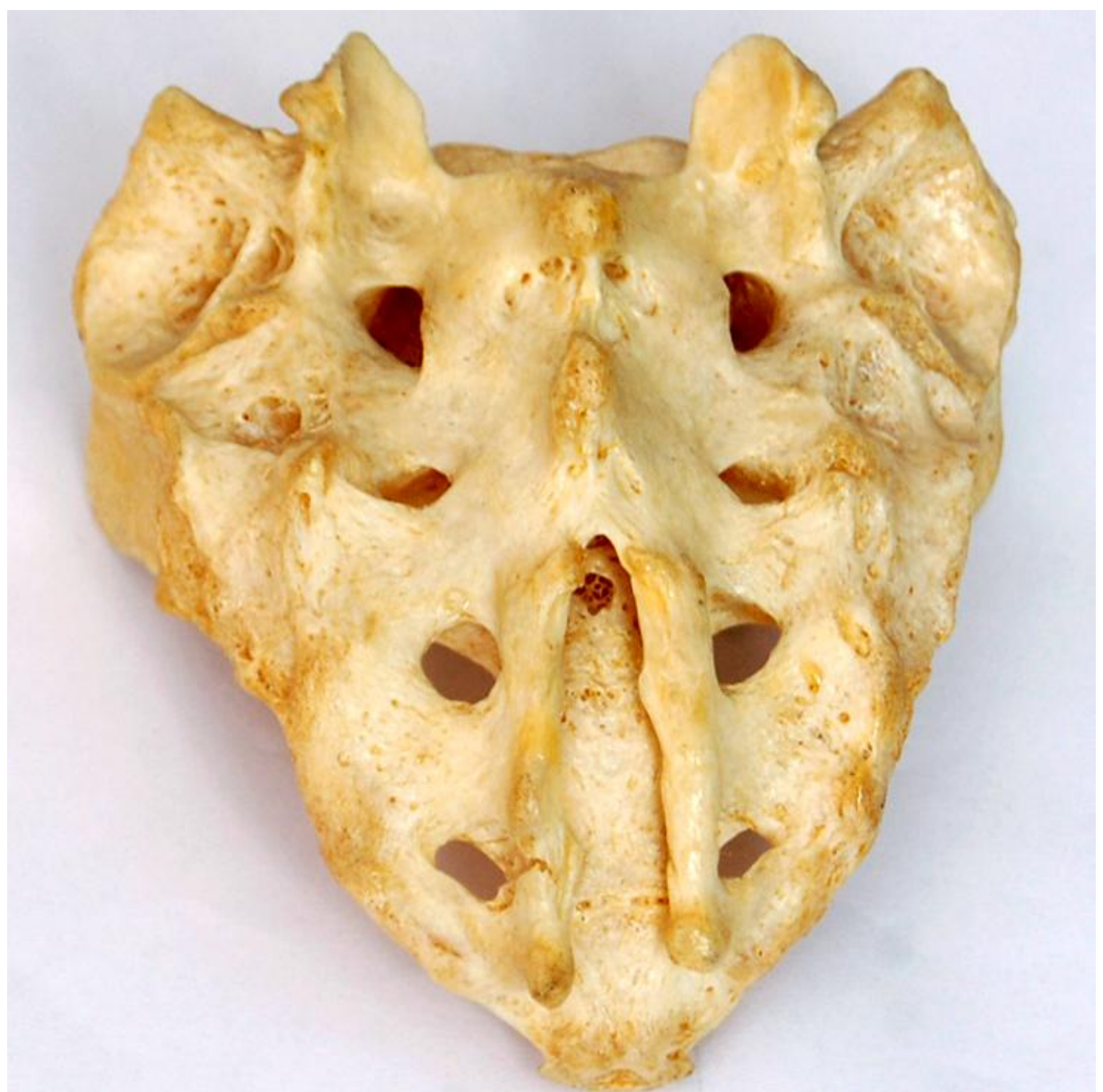

Figure: 2- Showing abnormally long sacral hiatus extending to a level just inferior to the spinous process of second sacral vertebra. 